\title{
Stability Analysis and Optimal State Feedback Control of Back-to- Back Converter
}

\author{
Fattah Hassanzadeh", Amin Hajizadeh and Fazel Abbasi" \\ Department of Electrical Engineering, Shahrood University of Technology, Shahrood, Iran
}

\begin{abstract}
Developing of transmission systems and using of different energy sources to supply the demand of network power makes that the using of power electronic converters are increased. Among the power electronic converters, Back to Back (B2B) converters are operated in the power system today's widely. These converters can be located in connection of distributed power generation systems to power network and in HVDC transmission systems.

In this paper stability analysis and controllability of B2B converters based on the average model in HVDC power transmission systems is studied. Also, optimal state feedback control under different conditions for B2B converter is proposed. Finally, simulation results are illustrated in order to verify the capability of proposed control strategy.
\end{abstract}

Keywords: Back to Back converter, Stability, Controllability, Regulation, Tracking.

\section{INTRODUCTION}

Today's the use of Back to Back Converters in power systems is increasing [1-6]. The usages of these converters can be pointed to connecting the distributed power generation systems to power network and in HVDC transmission systems $[1,7,8]$.

For example, in wind turbine systems, according to the changes in wind speed, power generation is fluctuated. One of the important problems that should be considered during the connection of wind turbine to main grid is proper synchronisation of this unit [2-5]. In this condition, B2B converters are used for synchronisation [2, 3]. Moreover, at the HVDC power transmission system, beginning of the line ac voltage convert to high voltage $d c$ and then, the dc voltage convert to ac voltage again with desired voltage and frequency level at the end of the transmission line $[1,7$, 8].

In all studies on the B2B converter, control of converter based on the real model has been considered. In [1] the steady state and dynamic performances of B2B converter based on voltage source converters during step changes of the active and reactive powers, balanced and unbalanced faults has investigated. In [2] converter control of wind turbine power generation system based on Optimal and DirectCurrent Vector Control was studied. In [3] a control strategy is considered for direct-drive permanentmagnet wind-power generator using sensor less backto-back PWM converter. Reference [4] studies control

\footnotetext{
*Address correspondence to this author at the Department of Electrical Engineering, Shahrood University of Technology, Shahrood, Iran;

Tel/Fax:+273-3300250; E-mail: aminhajizadeh@gmail.com

\#Co-Authors E-mails: fatahhasanzadeh1@gmail.com,

fazel.abbasi.7@gmail.com
}

strategy based on analytical strategies with aim to reducing destructive harmonics. In [5] converter control based on nonlinear decoupled control of back-to-back voltage source converter and in [6] limits of the neutralpoint balance in back-to-back-connected three-level converters were studied. In [7] a 36 step voltage source converter that it's output voltage steps has increased, is proposed. This 36 steps b2b converter can control active and reactive power of HVDC systems independently. In [8] a fast optimum predictive control strategy for bipolar B2B converter is proposed. This paper will study on stability and controllability of B2B converter based on average model and then, by designing the optimal state feedback investigate the regulation and tracking under different condition of active and reactive powers. This paper is as follows:

Section 2 presents a complete description of the plant based on average model. Section 3 studies the stability and controllability of plant and then, in section 4 by designing the optimal state feedback improve the stability. Section 5 contains tracking analysis of proposed controller. In section 6 for validation of control strategy, simulation results are presented. Conclusion is drawn in section 7 .

\section{B2B CONVERTER MODEL}

Figure 1 shows a simple model of B2B converter. It contains two power electronic converters. One of them works as a rectifier and converts the $A C$ voltage to $D C$ voltage and injects the power to DC link. Another converter works as an inverter and converts the DC voltage to $A C$ form and then injects the power to $A C$ grid through an inductance and a resistance per phase [2]. 


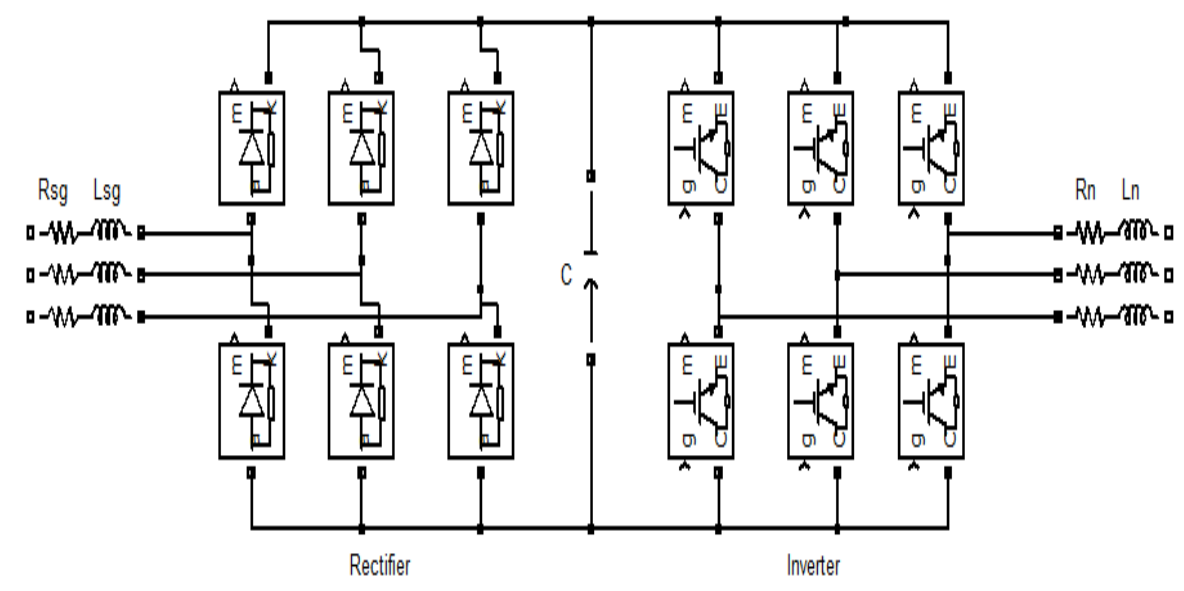

Figure 1: B2B Converter Circuit.

\subsection{Rectifier Converter Model}

The Equations that represent the behaviour of the rectifier in state space in dq frame follow from [2, 10, 11]:

$$
\left\{\begin{array}{l}
\left\{\begin{array}{l}
V_{s d}=-\left(R_{s} i_{s d}+L_{d} \frac{d i_{s d}}{d t}\right)-w_{e} L_{q} i_{s q} \\
V_{s q}=\left(R_{s} i_{s q}+L_{q} \frac{d i_{s q}}{d t}\right)+w_{e} L_{d} i_{s q}
\end{array}\right. \\
\Rightarrow\left\{\begin{array}{l}
\dot{i}_{s d}=-\frac{R_{s}}{L_{d}} i_{s d}-\frac{w_{e}}{L_{d}} L_{q} i_{s q}-\frac{V_{s d}}{L_{d}} \\
i_{s q}=-\frac{R_{s}}{L_{q}} i_{s q}-\frac{w_{e}}{L_{q}} L_{d} i_{s d}-\frac{V_{s q}}{L_{q}}
\end{array}\right.
\end{array}\right.
$$

Where $R_{s}$ and $L_{d}$ and $L_{q}$ are the resistance and $d-q$ axis inductance of rectifier side line respectively. $V_{s d}$ and $V_{s q}$ are $d$ and $q$ axis of rectifier side line.

\subsection{Dynamic Model of Inverter}

The proposed control strategy for inverter, have two main purposes [3, 12]:
1. Confidence of the quality of power injected into the network.

2. Minimizing the injected active and reactive power error.

Figure 2 shows inverter model [2, 11]. According to figure 2 , the equations that represent the behaviour of the inverter in state space model $[2,10,11]$.

$$
\left\{\begin{array}{l}
\left\{\begin{array}{l}
V_{d 1}=R_{f} i_{g d}+L_{f} \frac{d i_{g d}}{d t}-w_{s} L_{f} i_{g q}+V_{d} \\
V_{q 1}=R_{f} i_{g q}+L_{f} \frac{d i_{g q}}{d t}+w_{s} L_{f} i_{g d}+V_{q}
\end{array}\right. \\
\Rightarrow\left\{\begin{array}{l}
i_{g d}=-\frac{R_{f}}{L_{f}} i_{g d}+w_{s} i_{g q}-\frac{V_{d}}{L_{f}}+\frac{V_{d 1}}{L_{f}} \\
i_{g q}=-\frac{R_{f}}{L_{f}} i_{g q}+w_{s} i_{g d}-\frac{V_{q}}{L_{f}}+\frac{V_{q 1}}{L_{f}}
\end{array}\right.
\end{array}\right.
$$

Where $R_{f}$ and $L_{g d}$ and $L_{g q}$ are the resistance and $d-q$ axis inductance of inverter side line respectively. $V_{d 1}$ and $V_{\mathrm{q} 1}$ are $\mathrm{d}$ and $\mathrm{q}$ axis of inverter side line.

By combining equations (1) and (2), the equation that represents the behaviour of B2B converter in state space is obtained following:

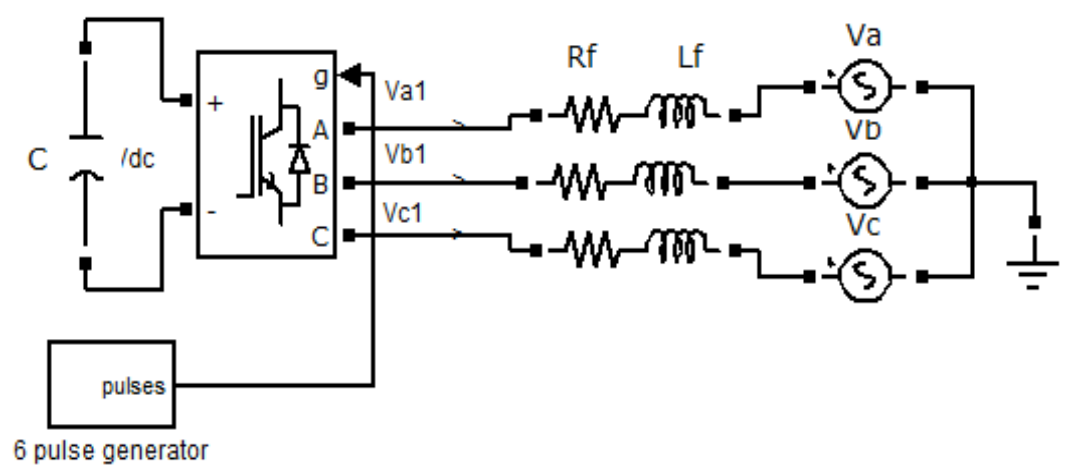

Figure 2: Inverter circuit. 


$$
\begin{aligned}
& \dot{X}=A X+B U+G \\
& {\left[\begin{array}{l}
\dot{i}_{s d} \\
\dot{i}_{s q} \\
\dot{i}_{g d} \\
\dot{i}_{g q}
\end{array}\right]=\left[\begin{array}{cccc}
-\frac{R_{s}}{L_{d}} & -\frac{w_{e} L_{q}}{L_{d}} & 0 & 0 \\
\frac{w_{e} L_{d}}{L_{q}} & -\frac{R_{s}}{L_{q}} & 0 & 0 \\
0 & 0 & -\frac{R_{f}}{L_{f}} & w_{s} \\
0 & 0 & -w_{s} & -\frac{R_{f}}{L_{f}}
\end{array}\right]\left[\begin{array}{c}
i_{s d} \\
i_{s q} \\
i_{g d} \\
i_{g q}
\end{array}\right]} \\
& +\left[\begin{array}{cccc}
-\frac{1}{L_{d}} & 0 & 0 & 0 \\
0 & -\frac{1}{L_{q}} & 0 & 0 \\
0 & 0 & -\frac{1}{L_{f}} & 0 \\
0 & 0 & 0 & -\frac{1}{L_{f}}
\end{array}\right]\left[\begin{array}{c}
V_{s d} \\
V_{s q} \\
V_{g d} \\
V_{g q}
\end{array}\right]+\left[\begin{array}{c}
0 \\
0 \\
\frac{V_{d 1}}{L_{f}} \\
\frac{V_{q 1}}{L_{f}}
\end{array}\right]
\end{aligned}
$$

In Table 1 the parameters of system is presented.

Table 1: Parameters of the System

\begin{tabular}{|c|c|}
\hline $\begin{array}{c}\text { Voltage and frequency of } \\
\text { grides }\end{array}$ & $\begin{array}{c}\text { 380v L-L } \\
\text { F=50Hertz }\end{array}$ \\
\hline \hline$R_{s}=R_{f}$ & $0.048150 h m$ \\
\hline$L_{d}=L_{q}=L_{f}$ & $\mathrm{mH}$ \\
\hline
\end{tabular}

\section{CONTROLLABILITY AND STABILITY ANALYSIS}

\subsection{System Controllability}

The main purpose of system controllability is state feedback designing. According to equation (4), the necessary and sufficient condition for the system controllability is that the matrix $w$ be full rank $[3,13,14]$.

$$
\left\{\begin{array}{l}
w=\left[\begin{array}{lllll}
B & A B & A^{2} B & \ldots & A^{n-1} B
\end{array}\right] \\
\operatorname{Rank}(w)=n
\end{array}\right.
$$
is [3]:

In multiple-input systems, condition of controllability

$$
\operatorname{det}\left(w^{T} \times w\right) \neq 0
$$

According to equations (4) and (5):

$$
\left\{\begin{array}{l}
\operatorname{det}\left(\mathrm{w}^{T} \times \mathrm{w}\right)=-4.88 \mathrm{e}+013 \neq 0 \\
\operatorname{rank}(\mathrm{w})=4
\end{array}\right.
$$

Therefore, the all states in model of B2B converter are controllable. So, state feedback control strategy could be designed for it.

\subsection{System Stability}

The stability is the most important characteristic for a control system. The stability of the closed loop system directly depends on root locus characteristic [3].

By using of the system eigen value, stability or instability of the system could be realized. If the eigen values locate in left side of imagine axis, it means that the system is stable, in otherwise, system is unstable.

Equation (7) is used to find the eigen values of the system $[3,13]$.

$\operatorname{det}(\lambda I-A)=0$

Where $\lambda$ is the roots of Equation (7) that are eigen values. According to equations (3) and (7):

$$
\left\{\begin{array}{l}
\lambda_{1,2}=-20.93 \pm 314 i \\
\lambda_{3,4}=-20.93 \pm 314 i
\end{array}\right.
$$

The real part of eigen values are negative, so system is stable.

\section{DESIGN OF OPTIMAL STATE FEEDBACK (LQR) CONTROL}

Figure 3 shows block diagram of state feedback control which has been implemented in this paper.

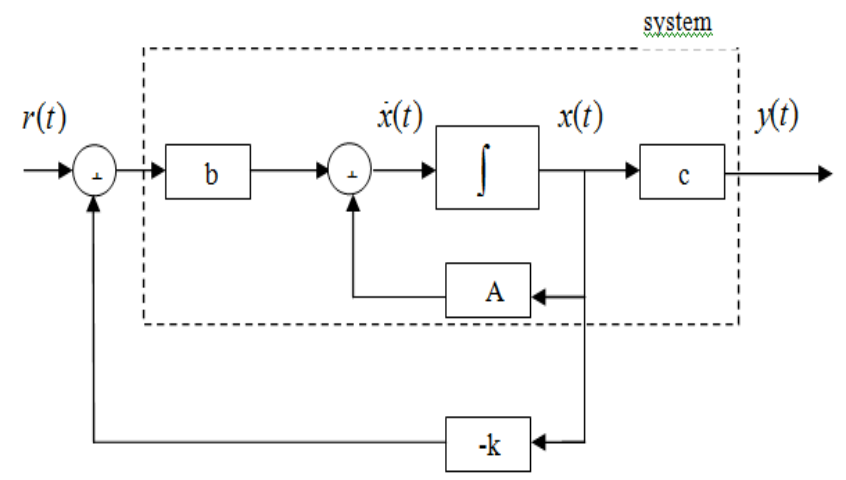

Figure 3: Block diagram of state feedback control.

In designing of optimal state feedback control, the control matrix $k$ is calculated from equation (9) [3]:

$k=R^{-1} B^{T} P$

Where $R$ is a positive definite matrix or a positive number, $B$ is input matrix and $P$ is calculated from rickety equations that are shown as follow: 
$A^{T} P+p A-P B R^{-1} B^{T} P+Q=0$

$\left\{\begin{array}{l}R=\rho I_{n} \\ Q=I_{n}\end{array}\right.$

Where $\mathrm{Q}$ is a positive semi-definite matrix and $\mathrm{n}$ is number of state variables.

According to Equations (9) to (11), $k$ is:

$\mathrm{K}=\left[\begin{array}{cccc}-0.95 & 0 & 0 & 0 \\ 0 & -0.95 & 0 & 0 \\ 0 & 0 & -0.95 & 0 \\ 0 & 0 & 0 & -0.95\end{array}\right]$

The system's eigen values after implementation of state feedback control are achieved as follow:

$\operatorname{det}(\lambda I-(A-B K))=0$

$\left\{\begin{array}{l}\lambda_{1,2}^{\prime}=-435 \pm 314 \mathrm{i} \\ \lambda_{3,4}^{\prime}=-435 \pm 314 \mathrm{i}\end{array}\right.$

By comparing $\lambda$ and $\lambda^{\prime}$, it can be seen that the stability of the system with optimal state feedback control has been better than the previous condition.

\section{REGULATION AND TRACKING ANALYSIS}

In this section the Regulation and Tracking problems will be described.

\subsection{Regulation Analysis}

For analysing the properties of the state feedback controller, first the closed-loop system in state space should be considered [13].

$\left\{\begin{array}{l}\Delta \dot{x}=A \Delta x+B \Delta u \\ \Delta y=C \Delta x\end{array}\right.$

All state variables and outputs set at zero point or origin of coordinates. However, in most practical problems in control systems, setting the system outputs at nonzero constant values is desired. This subject can be achieved by a small change in implementation of state feedback controller as follows $[1,3,7]$ :

Assume $y_{d}$ shows the reference input, that $y_{d} \neq 0$.

First, the steady-state variables and inputs are calculated for achieving to $y_{d}$. Now suppose that there is an answer for system, and it can be displayed as follow [3]:
$\left\{\begin{array}{l}x=M_{x} y_{d} \\ u=M_{u} y_{d}\end{array}\right.$

Like non-linear equations, it is defined the incremental variables as following equations (16):

$$
\left\{\begin{array}{l}
\Delta x(t)=x(t)-x \\
\Delta u(t)=u(t)-u \\
\Delta y(t)=y(t)-y_{d}
\end{array}\right.
$$

In this condition, the mathematical equation makes that $y(t)=y_{d}$, therefore, incremental variable should be zero, $\Delta y=0$, and this causes the $\Delta x$ be zero. So:

$\Delta x \rightarrow 0 \Delta y \rightarrow 0 \Rightarrow y(t) \rightarrow y$

For this purpose, the control signal is:

$\Delta u=-k \Delta x$

Where, by choosing a proper $k, A-B k$ be internal stable, optimal steady values also will obtain. Hence in main system, controller is as:

$$
\begin{aligned}
& u(t)=u+\Delta u=u+k \Delta x \\
& =u+k(x-x)=\left(M_{u}+k M_{x}\right) y_{d}-k x \\
& =u_{e x}-k x
\end{aligned}
$$

After designing $\mathrm{K}$ and calculating $M_{x}$ and $M_{k}$, it is not required using of incremental variables and the controller easily is implementable as shown in Figure 4 $[3,14]$.

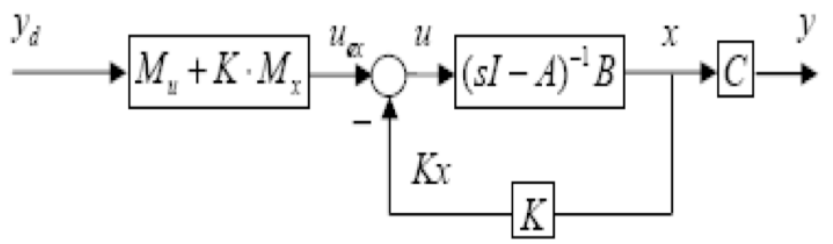

Figure 4: Implementing regulation controller without using incremental variables.

In Figure 4, $M_{u}+K M_{x}$ block is as feedback form. Then:

$\Delta \dot{x}=(A-B k) \Delta x$

$\left\{\begin{array}{l}x(t)=\Delta x(t)+x \\ u(t)=\Delta u(t)+u \\ y(t)=y_{d}+C \Delta x(t)\end{array}\right.$

Therefore, for designing the state feedback controller, it needs to consider that the regulated state be set on zero. By choosing an appropriate $k$, the 
matrix $A-B k$ be stable, then, this controller can be implemented on main system [3].

\subsection{Tracking Analysis}

The final form of regulation problem could be easily generalized to tracking form. However, here $y_{d}=y_{d}(t)$ that is a function of time, so, the feedback loop must be updated.

\section{SIMULATION AND RESULTS}

In this section, the simulation results based on average model are presented.

Figures 4 and $\mathbf{5}$, represented the response of the system without/with state feedback respectively.

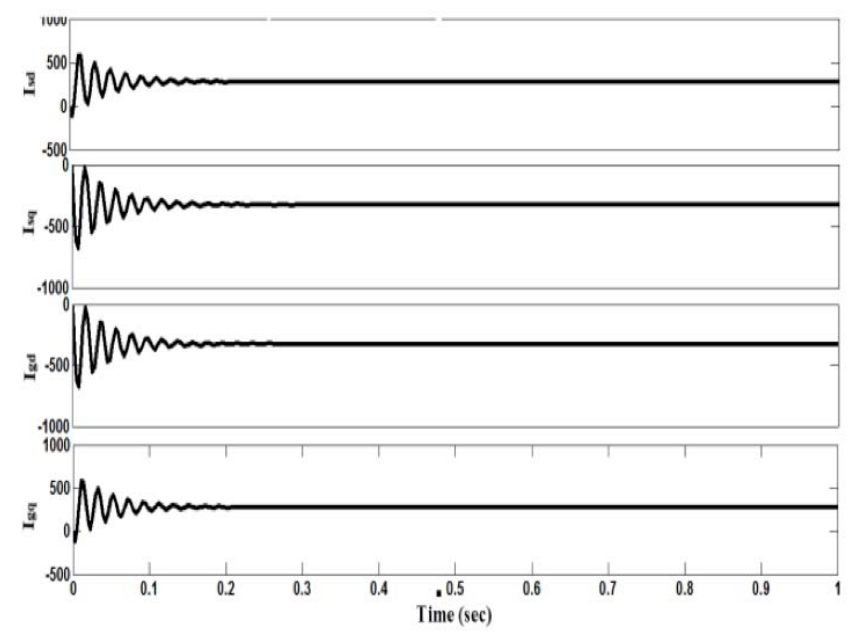

Figure 5: System response without state feedback.

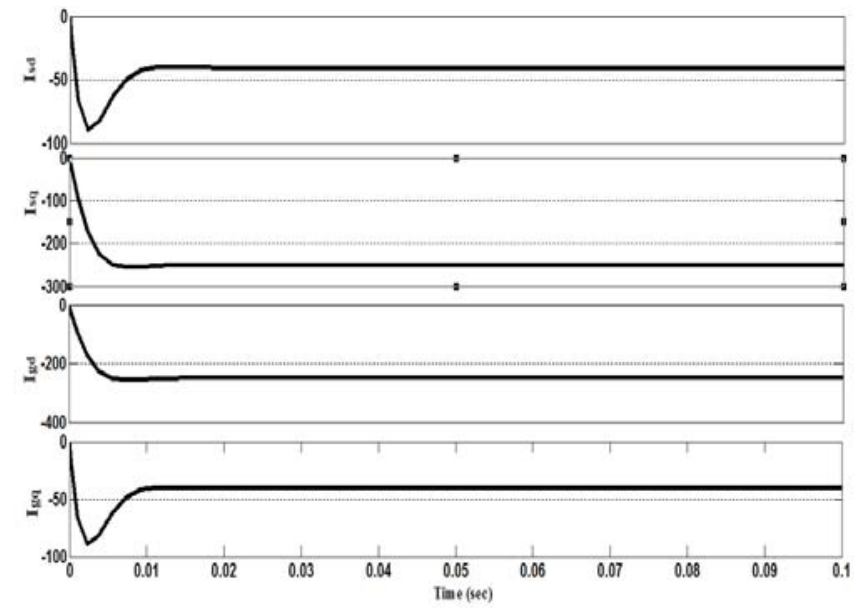

Figure 6: System response with state feedback.

According to Figures $\mathbf{5}$ and $\mathbf{6}$, it could be illustrated that, when state feedback controller is used, the state variables reach to steady state faster and transient state is reduces. After that, the regulation problem is considered. Thus, assume that injecting $50 \mathrm{kw}$ active power and 10kvar reactive power is our regulation purpose. Using equation (21), it could be calculated the $\mathrm{d}$ and $\mathrm{q}$ references current in dqo frame.

$\left[\begin{array}{l}P \\ Q\end{array}\right]=\frac{3}{2}\left[\begin{array}{cc}V_{d} & V_{q} \\ V_{q} & -V_{d}\end{array}\right]\left[\begin{array}{l}i_{d} \\ i_{q}\end{array}\right]$

Figure 7 show the reference currents in dq frame and figure 8 show the regulation result.
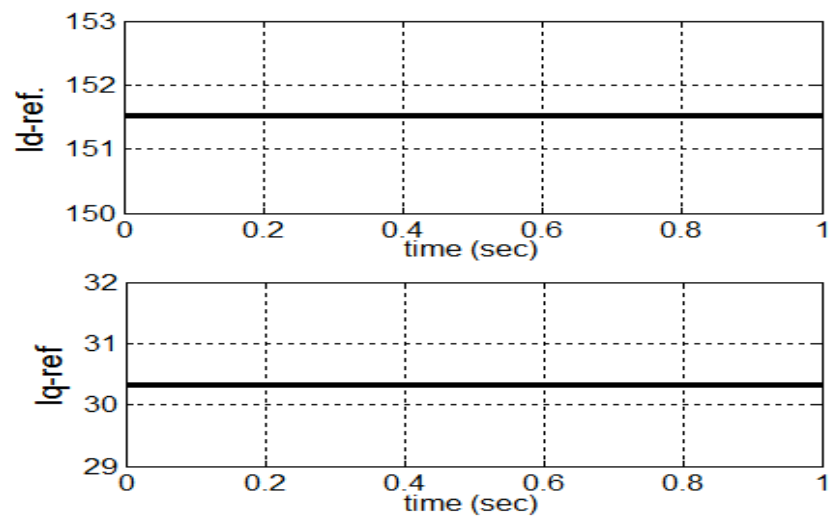

Figure 7: $d-q$ axis reference currents.
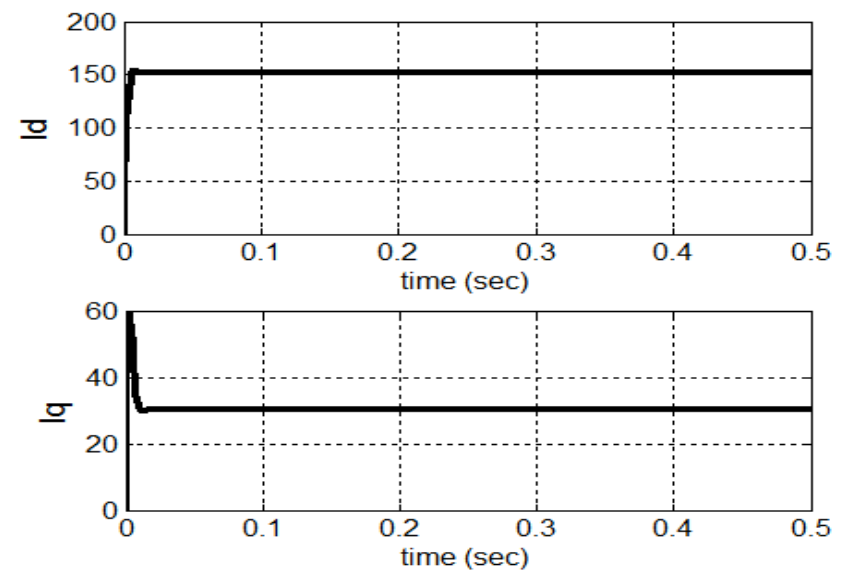

Figure 8: $d-q$ axis currents regulation results.

According to Figures 7 and 8 and comparing them, it could be illustrated that regulation has been performed correctly.

\subsection{Tracking}

In this situation, active and reactive power injected to power system to tracking purpose, is function of time, as Figure 9. Using equation (21) calculating the reference currents in dqo frame that are as Figure $\mathbf{1 0 .}$

Figure 11 show the tracking simulation results. It can be seen that B2B converter tracking the performed correctly. 


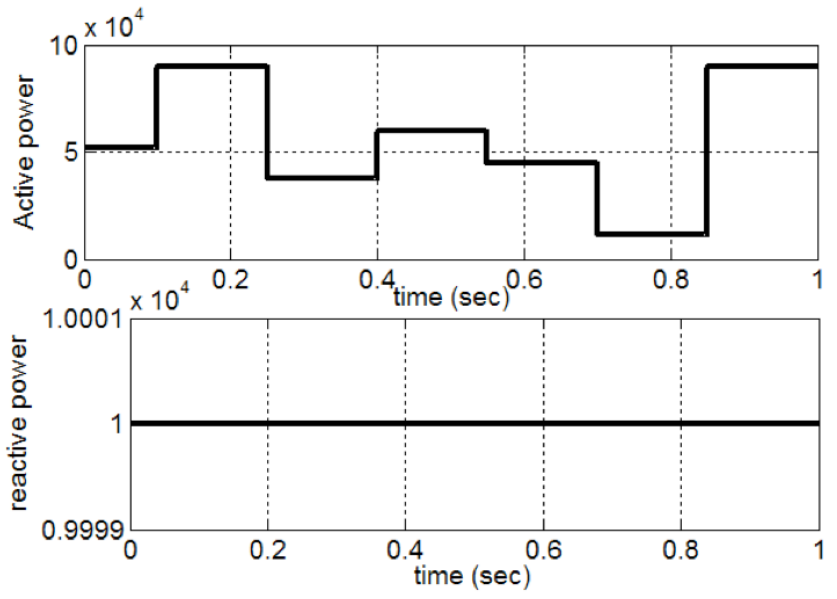

Figure 9: Active and reactive power injection to network.
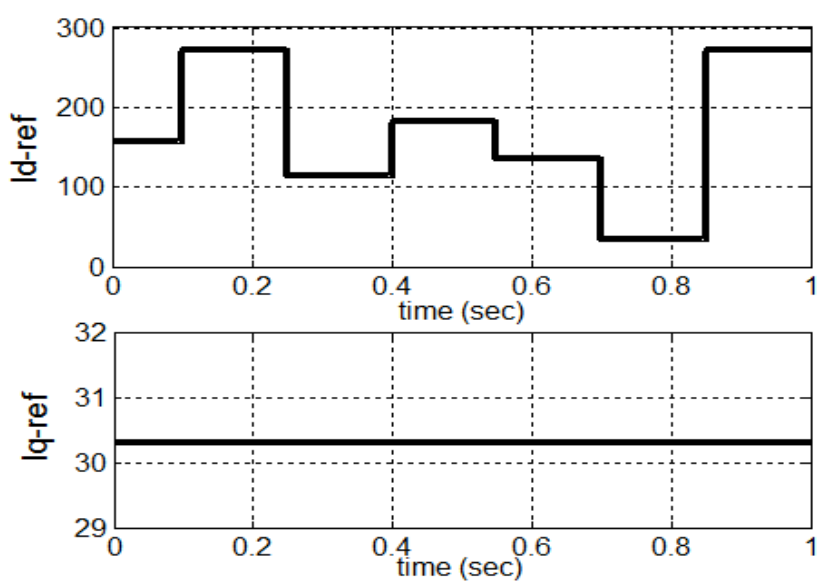

Figure 10: $d-q$ axis current references.
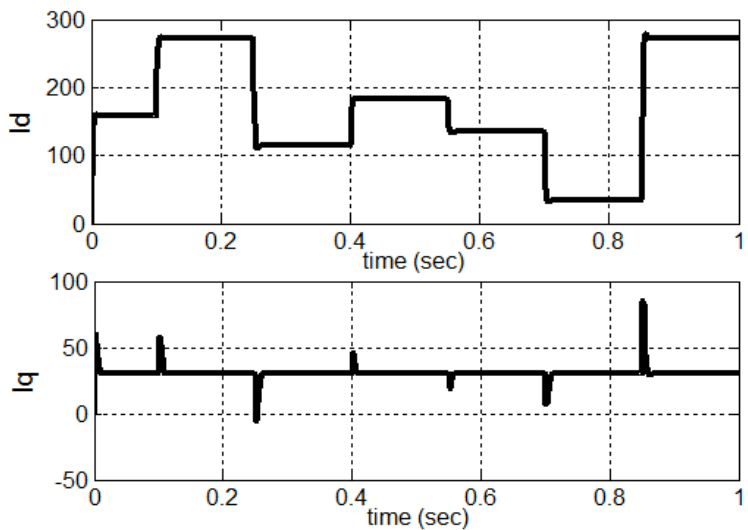

Figure 11: $d-q$ axis current tracking results.

\section{CONCLUSION}

In this paper the stability and controllability of B2B converter based on average model have been studied.
Then, by designing optimal state feedback (LQR) controller, the stability of the system has been improved.

Finally, the Regulation and Tracking has been investigated. Simulation results show that with step changes in active and reactive powers, dq currents change respectively. Moreover, regulation and tracking problems have been performed correctly to verify the capability of proposed control strategy.

\section{REFERENCES}

[1] Khatir M, Zidi S-A, Hadjeri S, Fellah M-K. Dinamic Performance of a back-to-back HVDC Station Based on Voltage Scource Converters. J Electric Eng 2010; 61(1): 2936.

[2] Li S, Haskew TA, Swatloski RP, Gathings W. Optimal and Direct-Current Vector Control of Direct-Driven PMSG Wind Turbines. IEEE Trans Power Electron 27(5).

[3] Taghi-Rad HR, Reviwe of Modern Control: state feedback, K.N. University of Technology, Tehran, Iran, Hall 2003.

[4] Huang K, Huang S, She F, Luo B, Cai L. A Control Strategy for Direct-drive Permanent-magnet Wind-power Generator Using Back-to-back PWM Converter. Project Supported by National Eleventh-five 863 Research Program 2010.

[5] Portillo RC, Prats MM, León JI, Sánchez JA, Carrasco JM, Galván E, Franquelo LG. Modeling Strategy for Back-to-Back Three-Level Converters Applied to High-Power Wind Turbines. IEEE Trans Indus Electron 2006; 53(5).

[6] Gan-Gui Y, Gui-Qiang J, Gang M, Jun-Hui L, Tao C, YaFeng $\mathrm{H}$, Jian $\mathrm{W}$. Dynamic Modeling and Nonlinear Decoupled Control of Back-to-back Voltage Source Converter 2009.

[7] Pou J, Pindado R, Boroyevich D, Rodríguez P. Limits of the Neutral-Point Balance in Back-to-Back-Connected ThreeLevel Converters. IEEE Trans Power Electron 2004; 19(3).

[8] Chaves M, Margato E, Silva JF, Pinto SF, Santana J. HVDC transmission systems: Bipolar Back to Back Diod Clamped Multilevel Converter with Fast Optimum-Predictive Control and Capacitor Balancing Strategy. Elsevier, Electric Power Systems Research 2011; 81: 1436-45

[9] Han B-M, Baek S-T, Bae B-Y, Choi J-Y. Back to Back HVDC System Using36-step Voltage Scource Converter. IEE J Generat Transmision Distribut 2006; 677-683.

[10] Abedini A, Nikkhajoei H. Dynamic model and control of a wind-turbine generator with energy storage. IET Renewable Power Generation 2010; 67-78.

[11] Ottersten R. On Control of Back to Back Converter and Sensorless Induction Machine Drive. Thesis For the Degree of Doctor of Philosophy 2003.

[12] Anaya-Lara $O$, Jenkins $N$, Ekanayake $J$, Cartwright $P$, Hughes M. Wind energy generation, Modelling and Control, John Wiley \& Sons, Ltd, 2009.

[13] Shinners M. Stanley, Modern control system theory and design, $2^{\text {nd }}$ ed. J. Wiley c 1998.

[14] Dorf C, Richard, Bishop H. Modern control system, Upper Saddle River, NJ: Prentice Hall 2001. 